\title{
Fuel's paradise
}

\section{The utopian urge to separate the world's nuclear-fuel cycles from national strategic ambitions has merit.}

n n 1972, Abdul Qadeer Khan, a young Pakistani engineer working at a uranium-enrichment plant in Almelo in the Netherlands, was able to walk out of the lab with the blueprints for advanced gas uranium centrifuges. Khan went on to become the father of Pakistan's atomic bomb, and created a nuclear-weapons black market network, exposed in 2004, spanning from labs and offices in Dubai, Malaysia and South Africa to clients in North Korea, Libya and Iran.

It is difficult to conclude what is most shocking: the shoddy security of the civilian nuclear industry, the unscrupulous scientist-accomplices in Khan's network, or that US intelligence agencies allegedly withheld information for well over a decade to protect US-Pakistan relations.

But they all add up to a stark reminder that the diversion of material from the civil nuclear industry remains the easiest stepping stone to nuclear-weapons prowess. The preventative oversight of the civil fuel cycle cannot necessarily be provided by plant operators, inspectors or governments. There is no regulatory requirement for a nuclear plant to be secure and 'proliferation resistant'.

Where then should efforts be focused to make the civil nuclear industry more secure? The answer is both simple and worrying. It has never been easier for the unscrupulous to construct a weapon. The most urgent challenge is to prevent anyone acquiring or producing the couple-of-dozen kilograms of fissile material required.

There are two points of danger in the nuclear-fuel cycle. One is at its front end: the enrichment of uranium to provide the low-enriched fuel needed to operate a reactor, a technology that is readily diverted to make highly enriched uranium for weapons. The other is at the cycle's back end: the reprocessing of spent fuel, which produces plutonium. Reprocessing is not in vogue and is uneconomic, although its use could grow if demand for nuclear energy puts pressure on uranium resources. For now, the pressing focus should be on uranium-enrichment technologies.

This challenge is all the more acute given that many countries, including Egypt and Saudi Arabia, are now turning to or at least considering nuclear power for strategic reasons that often go beyond their claimed motivations of energy independence and combating climate change. The existing enrichment capacity of countries such as Brazil and Japan makes them virtual weapons states - they could arm in months if they so wished.

Iran has made much of its 'inalienable right' under the 1970 nuclear non-proliferation treaty (NPT) to develop uranium-enrichment technology. Its insistence that this is a purely civilian endeavour rings manifestly false to many expert ears, for good reason. Beyond the various lines of evidence that support this scepticism lies the more general question of why bother. After all, neither Iran nor any other country has in principle any need to create national enrichment facilities. The international market for enriched uranium for civil use is efficient and well served, and good models for multilateral control already exist. Multilaterally owned or
"The concept of multilateral enrichment facilities is an idea whose time has come." operated fuel banks have been on the agenda since the detonation of the first nuclear bomb. The concept of multilateral enrichment facilities provided by existing technology owners is an idea whose time has come: we should embrace it (see page 380).

Such a solution requires a reinterpretation of the terms of the nuclear compromise embedded in the NPT, which offers countries unlimited opportunities for civilian nuclear development in return for forswearing proliferation. If new national enrichment facilities continue to be allowed, any nation that fears international sanctions somewhere down the line would have good reason to develop such facilities regardless of whether it also had military ambitions for the technology, as a matter of energy security. A fuel bank set in some way 'above politics' might help allay such fears - but that carrot would probably not, in itself, be enough. A further necessary condition for success would be that the nuclear-weapon states must themselves keep their part of the disarmament bargain (see Nature 451, 107; 2008).

In general, this journal believes that all nations should be allowed to develop scientific and technological capacities as they wish. There is no merit in developing nations sitting as passive consumers of the knowledge and know-how that the developed world already boasts. But some technologies are exceptional.

\section{Competition and noise}

\section{Mitt Romney's pledge to plough $\$ 20$ billion a year into energy research may signal an unseemly bidding war.}

t was, some commentators said, the mother of all panders. When Republican presidential contender Mitt Romney told a Detroit audience that he would increase US federal funding in energy research, automotive technology and materials science fivefold, to a cool $\$ 20$ billion a year, those inside the Beltway shrugged. In the
Motor City, though, the idea had more play. Romney's upbeat, goget-'em approach may have resonated with voters, and he duly won the Michigan primary the next day.

Romney is only one of half-a-dozen viable candidates for this November's presidential election, and his ambitious proposal is unlikely to be put into effect. It is nevertheless significant, because it points to how the United States may choose to respond to the danger of an economic recession that would spread to the country at large the woes already felt by many voters in Michigan.

President Bush and Congress are already scrambling to put together a stimulus package to stave off recession. Strategic responses - such 